Bikas S. Agayev , Tarlan S. Aliyev $^{2}$

${ }^{1,2}$ Institute of Information Technology of ANAS, Baku, Azerbaijan

1,2 depart6@iit.ab.az

\title{
CLASSIFICATION OF IMPACT FACTORS OF CERTAIN ELECTRONIC WASTE GROUPS ON HUMAN HEALTH
}

The article analyzes potential threats for human health posed by computer and medical electronic equipment waste. As an object of threat, the impact factors of substances and components used in these wastes are explored. Particularly, physiological and epidemiological, including partial environmental impacts of these factors are reviewed.

Keywords: waste, computer equipment waste, medical electronic waste, harmful substances and waste components, impact factors of electronic waste, safety of health, waste management.

\section{Introduction}

At present, information and communication technologies (ICT), including applied computerization and networking are the basic factors in the development of any field of activity. In modern medicine, the use of ICT, electrical and electronic equipment (hereinafter electronic equipment - EE) is manifested in the most concentrated form. However, as it is known, until the second half of the nineteenth century, doctors were limited to the tools for the measurement of pulse on wrist, visual examination of tongue and eyes, rashes on body, and faces. They were conducting a dialogue with patient/nurse as an interview using simple tools for the diagnosis and treatment.

From the second half of the nineteenth century, the main scientific discoveries were made in the field of electricity and magnetism, which were used in medical practice, perhaps earlier than in other areas of human activity. In the twentieth century, revolutionary discoveries and inventions in the field of semiconductor physics, computer and network technologies and techniques gave impetus to the intensive development of medical practices and, accordingly, led to significant increase in the equipment stock in this field.

Numerous medical electrical and electronic equipment (hereinafter medical electronic equipment - MEE) is also intensively used in the field of medicine in Azerbaijan. In recent years, along with the newly adopted healthcare frameworks, state programs, increasing number and quality of medical services provided, and improvement of technical support of medical institutions, there has been a sharp increase in the use of preventive, diagnostic, therapeutic and rehabilitation equipment. Undoubtedly, this positively influences the availability and quality of medical services rendered to the population. However, the abovementioned poses some challenges. The essence of these problems lies in the fact that most MEE and their wastes (hereinafter medical electronic equipment waste - MEEW) as potential sources of ecological, epidemiological, toxicological and radiological hazards are intimidating human health and damaging the environment.

These threats are caused both by damaging substances in MEE design and various radiations of electromagnetic and ionizing origins posed by them, and noise, formation of certain chemical compounds, as well as by the transition of MEE to the waste discharge at the end of life cycle.

In case of non-compliance with the instructions of MEE specified in the project documentation, including the loss of consumer properties, the transition to waste and inadequate use, MEEW are becoming a source of serious threats to human health and environment.

This problem is manifested in the most acute form in countries where centralized processing and full-featured management system for MEEW (waste documentation, selective collection, transportation and storage, primary and secondary processing, detoxification or their destruction) are not available. Handling of MEEW belonging to the class of toxic wastes, namely class $\mathrm{G}$, together with mixed solid household waste. Being thrown on landfills, they are exposed to external factors such as sunlight, rainfall, wind, ignition, etc., decomposing and polluting the atmosphere, soil, groundwater and water basins. On the other hand, the objective of new waste management 
strategy outlined in the report of the Commission "Our Common Future" at the UN General Assembly in 1987 is the reasonable use and conservation of natural resources for future generations. This involves the development of a closed cycle of economic activity, in which noble and rare metals and other useful substances and materials should be extracted from waste and reintroduced into the economic circulation, replacing the primary natural resources. Therefore, the development of a MEEW management system as an integral part of waste management system is very important and urgent task for each country.

The article explores the impact of MEE and their wastes on human health and environment.

\section{Impact factors, substances and components of medical electronic equipment and their wastes}

Technical literature provides different approaches to the classification of medical equipment. For example, they can be classified by purpose (consumer properties):

- preventive;

- diagnostic;

- medical;

- rehabilitation;

- equipment for administrative and management activities.

MEEW, from our point of view, should be classified taking into account the range of their epidemiological, toxicological and radiation effects:

- non-hazardous (inert) waste;

- hazardous waste;

- extremely hazardous waste;

- radioactive waste.

The further development of telemedicine, mobile healthcare, medical nanotechnology, computer diagnostics and other promising medical practices is estimated to lead to the emergence of new classification groups and a sharp increase in diversity of equipment.

According to sanitary and hygienic rules and norms, the following physical factors and substances contained in MEE are potential threats to human health and environment:

Electromagnetic waves (electromagnetic radiation - ER). ER is revealed by the impact of electromagnetic field on environment due to electric current. The following types of ER cause potential threats to human health and the environment [1]:

- radio waves - $30 \mathrm{kHz}-300 \mathrm{GHz}$;

- infrared waves - $300 \mathrm{GHz}-429 \mathrm{THz}$;

- ultraviolet waves $-3 \cdot 10^{5} \mathrm{THz}-3 \cdot 10^{7} \mathrm{THz}$;

- ionizing radiation $-3 \cdot 10^{7} \mathrm{THz}>6 \cdot 10^{10} \mathrm{THz}$.

For physical characteristics, the latter group of waves may include x-ray, alpha, beta, gamma radiation and neutron particles.

Radio waves. Radiation from radio waves occurs due to vacuum electronics (microwave lamps, magnetrons, etc.), mobile phones, Bluetooth devices, Wi-Fi network wireless devices, etc.

According to the sanitary norms, permissible values of the electromagnetic field intensity is $25 \mathrm{~A} / \mathrm{m}$ in the frequency range $5 \mathrm{~Hz}-2 \mathrm{kHz}$ and $2.5 \mathrm{~A} / \mathrm{m}$ in the frequency range $2 \mathrm{kHz}-400 \mathrm{kHz}$ at a distance of $50 \mathrm{~cm}$ from the source; a magnetic flux density is $250 \mathrm{gTl}$ in the frequency range $5 \mathrm{~Hz}-2 \mathrm{kHz}$ and $25 \mathrm{gTl}$ in the frequency range $2 \mathrm{kHz}-400 \mathrm{kHz}$ and a surface electrostatic potential of $500 \mathrm{~V}$.

Exceeding one of the three sanitary norms leads to an increase in heavy ions in the room causing eyes reddening, headaches, fatigue, hair loss, eczema, allergies and other symptoms.

Radio waves also impede the normal operation of electrical appliances. For example, the electromagnetic radiation generated by the pacemaker above the permissible value is fatal for a sick heart [2]. 
Infrared radiation (IRR). It is used for therapeutic purposes in small doses. This is due to the thermal effect produced by IRR in the subcutaneous tissues. However, if the dose and time of radiation exceeds, the IRR causes a deep overheating of tissues, which is revealed with water-salt imbalance and accompanied by diseases of skin, eyes, and brain disorders.

Ultraviolet radiation (UVR). In small doses, UVR has antibacterial properties and is beneficial for organism and promotes the generation of vitamin D. However, exceeding the maximum dose causes skin burns, increases the risk of malignant tumors, cataracts of eyes and other diseases.

Ionizing radiation $(I R)$. IR is associated with the process of attaining energy of X-ray and gamma radiation and alpha, beta and neutron particles from atoms of some substances. Radioactivity is detected in the case of substance atoms fission and when IR energy flow is generated. This process shapes the radionuclides. Thus, the streams of elementary particles spread in environment and penetrate into living organisms. In certain doses (power and duration of radiation), IR changes the atomic nucleus of living tissues and, as a product of nuclear reaction fission, transforms them into charged ions. As a result, the normal course of biological reactions in tissues is disrupted. This, in turn, can cause acute reactions such as skin redness, hair loss, radiation burns or radiation syndrome [3-5].

Currently, real sources of IR are both acting MEE actively using ER and radionuclides, including their wastes (X-rays, magnetic resonance, computer tomography and radio-therapy machines and some consumables).

Sound and noise are generated when MEE is enabled. In the technical literature noise is defined as an undesirable level of sound creating uncomfortable conditions for a person.

At present, the terms as "acoustic ecology" and "noise pollution" are introduced for quantitative and qualitative measurement of noise.

The actual boundary between sound and noise depends on the characteristics of the hearing aid (sound receiver) of a person and widely varies. In general, generated sounds are the waves spread in a solid, liquid or gaseous medium and perceived by ear (receiver) as hearing senses.

For the characteristics of sound effect on a person, the followings are acceptable: pitch of sound - its frequency (infrasound with frequency f $<20 \mathrm{~Hz}$, ultrasound with frequency f $>20 \mathrm{kHz}$ ), spectral composition (broadband more than 1 octave, tonal 1/3 octave band), level change by time (constant and variable levels - respectively unchanged within 8 hours or changes over $5 \mathrm{~dB}$ in the same interval). Typically, due to the uncertainty of the sound characteristics, sound level equivalent is used rather than sound level.

If a short-term effect of sound above the norm (noise) causes a sense of anxiety, discomfort, nervous excitement, then prolonged exposure to excessive noise damages the hearing aid and, as a consequence, leads to hearing loss (deafness). The studies show that noise negatively affects the normal functioning of organism, and has psychological (nervous breakdowns, stress, anxiety), physical (disturbance interfering the communication) and physiological (circulatory disorders, deafness, tinnitus - presence of nonexistent sounds, hyperacusis - abnormally acute hearing or painful sensitivity to audible sounds, diplacusis - violation of auditory perception, in which the same tone is perceived differently by right and left ear) effects. There are reliable evidences that extreme noise is used to destroy living organisms, including humans. For example, in the Middle Ages, there was an "under the bell" torture, when the sound of the bell was gradually killing a man. There are numerous cases when dolphins and whales were thrown ashore losing their orientation due to loud sonar sounds, and the development of plants was suspended due to loud noise.

Due to the damaging impact of noise on human life and health, its quantitative and qualitative indicators, including the indices of its harmful sources, are regulated by the relevant regulatory and legal acts (NRAs). Currently, in the member countries of the European Union (EU) and in the Russian Federation, the maximum accepted noise level is within 85-90 dB, and the noise level of $100 \mathrm{~dB}$ is permissible for short-term exposure within 15 minutes at an 8-hour working day [6]. 
Sanitary and epidemiological rules and norms developed in the Soviet period and Russia with the index " $\mathrm{R}$ " are also applied in the territory of Azerbaijan.

For comparison, the absolute silence is $0 \mathrm{~dB}$, normal tone of conversation - 30-40 dB, noise created by the sports racing car - 90-95 dB, noise of airplane take-off - $110 \mathrm{~dB}$, noise of music in the celebration palaces measured at a standard point at a distance of $1 \mathrm{~m}$ from the sound source at a height of $1 \mathrm{~m}$ from the floor reaches $120-125 \mathrm{~dB}$, and noise at the epicenter of a nuclear explosion - $200 \mathrm{~dB}$. Thus, 20-30 dB is considered to be a comfortable level, 60-90 dB - level of anxiety, 120$130 \mathrm{~dB}$ - level of pain, 140-150 dB - level of intolerance causing irreversible deafness, and 190$200 \mathrm{~dB}$ - fatal level.

Some IEAs contain chemical elements and their compounds, which are inert and unsafe in terms of operational rules according to the degree of damaging effects on human health and environment. However, when becoming waste and under certain conditions, as well as in case of improper disposal and recycling, they can turn into source of danger.

Computer and information and communication systems used for medical purposes, including lighting devices, chemical power supply for direct current along with ferrous metals, glass and wood contain colored, noble, rare earth and heavy metals and their compounds, as well as radioactive elements and their isotopes. Furthermore, high-molecular compounds, for example, polypropylene, polybromobiphenyl and its ethers, and polyvinyl chloride are widely used. By the degree of exposure some of these substances and their compounds can be toxic, radioactive, irritating, carcinogenic, infectious, teratogenic and mutagenic and may have a destructive effect on health human and environment.

As it is known, health facilities, regardless of profile, generate damaging waste containing various fractions. Five hazard classes of waste generated by the health facilities are distinguished in terms of their epidemiological, toxicological and radiation risks [7]:

- Class A - epidemiologically safe waste approximate to solid household waste for its composition;

- Class B - epidemiologically hazardous waste;

- Class B - epidemiologically extremely hazardous waste;

- Class G - toxicologically hazardous waste;

- Class D - radioactive waste.

Toxicologically hazardous wastes (class D), in turn, are structured into four hazard classes according to the degree of their toxicological hazard [8]:

- $\quad$ Class 1 - extremely hazardous waste;

- $\quad$ Class 2 - highly hazardous waste;

- $\quad$ Class 3 - moderately hazardous waste;

- $\quad$ Class 4 - low hazardous waste.

Here, the term "harmful substance" is specified, in accordance with GOST 12.1.007.76, as "a substance that, in case of contact with human body if safety requirements are violated, may cause work-related injuries, occupational diseases or abnormalities in health detected by modern methods both in the process of work and further life of the present and future generations" [9].

In all developed and some developing countries, electronic waste, including MEEW is handled based on special legislative framework. For example, in the EU countries, a whole package of normative legal documents (program acts - general framework documents, over and above regulatory acts, such as directives, contracts, instructions, etc.) has been developed for the management of electronic waste based on environmental law.

In these countries, hazardous wastes handling is governed by the directives 2012/19/EU of the European Parliament and the Council of 4 July 2012 on waste electrical and electronic equipment (latest ediciton) [10], 91/689/EEC "On hazardous substances" [11], 2011/65/EU Restriction of Hazardous Substances Directive - RoHS "On the restriction of the use of certain hazardous substances in electrical and electronic equipment " [12] and many other documents. For 
example, the last directive prohibits the use of mercury, cadmium, lead, chromium VI, polybrominated biphenyls (PBB) and polybrominated diphenyl ethers in the equipment manufacturing. The ban on the import of products to the territory of the EU without the certificate ROHS-2 (2nd edition), confirming the absence of hazardous substances, has passed into law since January 2013. According to the same directive, starting from July 22, 2014 to July 22, 2016, the limits for the use of hazardous substances are prescribed in stages for groups of equipment: the mass of these substances should not exceed $0.1 \%$ of the total mass of the structure (restriction for cadmium and its compounds $-0,01 \%$ ).

RoHS Directive is taken as fundamental for the development of national regulations of some East Asian countries [13].

Since July 2017, the State Bureau of Standards, Metrology and Inspection (BSMI) of the Taiwanese authority will be enforcing its own RoHS requirements. These requirements are similar to the RoHS requirements of China [14].

We briefly review the substances in the composition of the MEE and MEEW particularly harmful to human health and environment.

Rare earth minerals (metals) are used in a number of magnetic nuclear MEE, TVs, smartphones, fluorescent lamps, etc. If its compounds are ingested into the human body, they can cause pancreatic diseases, lung cancer and leukemia.

Bromine-containing substances, including polybromodiphenyl ethers (as flame retardant), are used to increase the fire resistance and plasticity of MEE components, for example, cables and wires, various plastic products. The vapor and smoke of these ethers ingested into the human body (at the stages of production and installation of EE) have a carcinogenic effect and irritate the mucous membranes of eyes and the respiratory tract, which causes allergic reactions, nausea, vomiting. They also suppress the activity of the central nervous system and promote the development of skin diseases. In addition, diphenyl is toxic to kidney, liver, cardiovascular and nervous systems.

Polyvinyl chloride is high-molecular plastic mass used in the manufacture of the structural elements of MEE, and as an isolating material in cables and wires (with the addition of flame retardants). Under the influence of sunlight and, in particular, during combustion, extremely harmful (class I) carcinogenic dioxins are formed. Dioxins intrude the hormonal balance and reproductive functions of body and cause the growth of malignant tumors.

Phthalates. These are plasticizers used to increase the elasticity and strength of PVC, rubber and other materials. They are part of plastic structures, cables, wires and coating materials. They are referred to a group of toxic substances and have the property of spontaneous release, separation from the product and mixing with air. They can penetrate the body (in the form of monophthalates) through air, water, food and skin and spread to all internal organs. They may cause diseases of kidney, liver and hormonal system. They are referred to the second class of toxic substances.

Tin and lead are referred to the group of heavy metals and used for soldering. To improve the quality of soldering, cadmium, bismuth and antimony, which increase the level of danger, are added. Gas of these substances disrupts the usual activity of the central nervous and reproductive systems and kidneys. They are referred to the hazard class I.

Mercury. Extremely hazardous substance. The use of mercury is regulated by the Minamata Convention, which sets out the actions of the international community to reduce (down to a complete exclusion) the production of mercury-containing devices (especially, medical equipollents). Mercury is recognized as a substance with significant neurological and other effects on human health, with particular concern for its harmful effects on fetus and infants [15].

Chemical power supply of direct current are disposable batteries and repeatedly rechargeable batteries. They are widely used in mobile MEE for autonomous power. After use (for a battery this is a finite number of discharge-charges), these elements become waste. They include (depending on types) mercury, tin, zinc, cadmium, nickel, lithium, manganese and alkalis. The first four elements are 
very dangerous. Moreover, in case of ignition of power supply, destructive complex compounds and gaseous substances are emitted. Experiments show that highly toxic chemical compounds in the battery used only once can spoil $1000 \mathrm{~m}^{3}$ of water. When storing batteries and accumulators on landfills of solid household waste, these chemical compounds can easily leak into groundwater as a result of erosion of metal coatings. At the same time, crop and livestock products at the land sites close to the landfill become useless. Specifically, in Russia, highly toxic waste of power supply is stored at a specialized site Krasnyi Bor dump site for further processing in the future due to the lack of proper technology at the present time.

In the EU, according to Directive 2006/66 / EC "On batteries and accumulators" [16], emission of these devices together with household waste is prohibited. There are various sanctions on the violations of the provisions of the directive. Thus, in Germany, a fine of 300 euros is charged for the emission of batteries and accumulators together with household waste. Other EU countries, the United States and Canada also apply similar penalties.

In Azerbaijan, there are no enterprises for the disposal of these elements and, at best, they are simply buried in landfills. For example, according to the statistical bulletin "Re-use of raw materials" of the State Statistics Committee of Azerbaijan in 2015, due to the lack of an appropriate management system and processing infrastructure for waste landfills, 0.2 tons of mercurycontaining sludge, 3.9 tons of fluorescent lamps, 27 tons of batteries and accumulators, 717.9 tons of medical waste (the list is not disclosed) are released in waste landfills [17]. Batteries and accumulators are classified as Class I (extremely dangerous) for the degree of danger. They cause serious consequences due to heavy metals in their composition.

Computer technology. Monitor, system unit and toners of laser printer cartridges pose a danger for human. At present, computer monitor park has been updated and liquid crystal display monitors appeared. "Electronic garbage" of old types of cathode-ray tube monitors (CRT) are predicted to run out only by 2020-2025. However, the main problem is that CRTs require special disposal.

Undoubtedly, the intensity of radiation and the load on sight from liquid crystal display monitors and their varieties are considerably minor. However, extremely dangerous heavy metals, such as mercury, cadmium and tin, are still used in their manufacture. In case of the breakdown (depressurization) of these monitors, mercury gas may pose a serious threat to human.

The high clock frequency (up to $4 \mathrm{GHz}$ ) used in system blocks of computers also has some negative consequences at certain distances from the block. For example, de-ionization of air surrounding the system block occurs, consequently, the risks of allergy and respiratory diseases increase [18].

Laser cartridges. Powder-toner used in laser printer cartridges is potentially dangerous in case of non-compliance with the instructions and utilization. The main components of toner are soot and magnetite. Iron, titanium, aluminum oxide, benzene, and in some cases - dibutyl and tributyl in admissible (safe) concentrations, are added to toner to improve its quality. The size of microparticles of toner is 3-4 microns, which is 10-15 times smaller than the size of ordinary dust. They are odorless and invisible to the naked eye. When a cartridge is depressurized, the microparticles of toner spread in the air and penetrate into lungs through the respiratory system and accumulate in them causing diseases such as asthma and silicosis [19]. Personal protective equipment (respirator and gas mask) cannot detain microparticles of this size.

Lighting systems $(L S)$. In medical practice, LSs are used for preventive and therapeutic purposes and for lighting. To assess the effects of LS lamps on human health, in this study, we apply the standard of the International Electrotechnical Commission 62471/2006 "Lamps and lamp systems. Light-biological safety" [20]. This standard normalizes the integral estimates (radiation type, intensity, design, etc.) of the exposure to LS and identifies four risk groups for human within certain period in the artificial lighting zone:

- risk group 0 (without risks) - maximum exposure time is more than 10,000 seconds,

- risk group 1 (low risk) - exposure time 100 - 10,000 seconds; 
- risk group 2 (moderate risk) - exposure time 0.25 - 100 seconds;

- risk group 3 (high risk) - less than 0.25 seconds.

The risk group 0 includes conventional incandescent lamps and halogen incandescent lamps, and the groups of risks 1 - 3 - LED lamps (Light Emitting Diode).

White light emission of LED-lamps is achieved through the interaction of LEDs that generate blue and yellow waves. The frequency of blue waves falls within the range of UFR. Waves of the range of UFR have harmful mutagenic effect on the tissues of eye, and especially on retina. This is explained by the fact that photons of UFR cause macromolecular chemical reactions in retina, which origins structural changes in it. Studies show that blue LED with a radiation flux of $0.07 \mathrm{Watt}$ refers to the 1st risk group. The blue LED with a radiation flux of 0.5 Watt at a maximum exposure time of 15-20 seconds is referred to the 2nd risk group. In the same risk group, the exposure time should be reduced to 3-4 seconds with an increase in the radiation flux to 1 Watt [21].

Fluorescent lamps $(F L)$ are the source of gas discharge light. When voltage is applied to the electrodes of a lamp filled with mercury vapor, an electrical discharge occurs, which causes UFR. When UFR interacts with phosphor applied to the inner surface of the lamp, visible white light is emitted.

The harmful effect of FL is due to the following factors:

- FL emission spectrum differs from sunlight and a human perceives the colors of objects in a distorted way;

- fluctuations (pulsations) of light waves and stereoscopic effect;

- release of mercury vapors into the environment when a lamp is depressurized.

Distortions in the light perception of objects, including information on their movement (rotation), which do not coincide with reality, cause discomfort, sense of fatigue, and in certain circumstances, an emergency situation, for example, for a working lathe. In the EU member countries, since 2003, the use of single-layer luminophor FL with a monochrome spectrum has been prohibited in residential and working premises, if people stay in these premises more than the excess time allocated for lighting.

\section{Conclusion}

The article reviewed potential threats and negative consequences generated by electromagnetic waves, noise, ionizing radiation, and lighting systems. The physical factors and phenomena that occur during production, functioning and, at the end of the life cycle of MEE, when they are converted into MEEW, including mechanisms of their impact on human health and environment, were analyzed. It was concluded that radioactive, irritating, carcinogenic, infectious, teratogenic, mutagenic and other properties appeared in the medical practice of electronic equipment and its waste. Under certain conditions, harmful substances and their compounds were formed that affect human health and cause ecological, epidemiological and toxicological threats. It was shown that MEEW had differences for its structure and methods of processing. Therefore, creating safe working conditions for medical personnel and the corresponding infrastructure for collection and processing of MEEW for the improvement of the quality of life of medical personnel and people was considered to be a very urgent task. The necessity of creating an effective management system for the MEEW covering the lifecycle from the formation stages to the complete processing and safe disposal was verified.

The work was implemented with the financial support of the grant competition projects of the Science Foundation of the State Oil Company of the Republic of Azerbaijan in 2017.

\section{References}

1. State system of sanitary and epidemiological regulation of the Russian Federation. Federal sanitary rules, norms and hygienic standards, SanPiN 2.2.4 / 2.1.8.055-96. Electromagnetic radiation of the radio frequency range, http://www.yourdom.ru/sanpin/224_218055-96

2. Influence of radio waves on the human body, http://www.medbe.ru/news/nauka-i- 
tekhnologii/vliyanie-radiovoln-na-organizm-cheloveka/

3. State system of sanitary-epidemiological regulation of the Russian Federation. Federal sanitary rules, norms and hygienic standards, SP 2.6.1.799-99. Ionizing radiation, radiation safety. Basic sanitary rules for ensuring radiation safety, http://www.files.stroyinf.ru/data1/7/7569

4. I.N.Bekman. Ionizing radiation and its field, Lecture, http://www.profbeckman.narod.ru/YadFiz.files/L13.pdf

5. WHO. Ionizing radiation, health effects and protective measures. Information Bulletin, No. 371, April 2016.

6. State system of sanitary-epidemiological regulation of the Russian Federation. Federal sanitary rules, norms and hygienic standards, SN 2.2.4 / 2.1.8.562-96. Noise in the workplace, in the premises of residential, public buildings and on the territory of residential buildings, http://www.rosteplo.ru/Npb_files/npb_shablon.php?id=711

7. State system of sanitary-epidemiological regulation of the Russian Federation. Federal sanitary rules, norms and hygienic standards, SanPiN 2.1.7.2790-10. Sanitary and epidemiological requirements for the management of medical waste, http://www.sisterflo.ru/sanpins/SP2790-10.php

8. State system of sanitary and epidemiological regulation of the Russian Federation. Federal sanitary rules, norms and hygienic standards, SP2.1.7.1386-03. Sanitary rules for determining the hazard class of toxic production and consumption wastes, http://www.ohranatruda.ru/ot_biblio/normativ/data_normativ/39/39761/index.php

9. GOST 12.1.007-76 *. Harmful substances. Classification and general safety requirements. http://www.docs.cntd.ru/document/5200233

10. Directive 2012/19/EU of the European Parliament and the Council of 4 July 2012. On waste, electrical and electronic equipment,

11. http://www.eur-lex.europa.eu/legal-content/EN/ALL/?uri=CELEX:32012L0019

12. Council Directive 91/689/EEC of 12 December 1991. On hazardous wasteç, http://www.coprocem.com/documents/hazardous-waste-directive-91-689-eec.pdf

13. Directive 2011/65/EU of the European Parlament and of the Council of 8 June 2011. On the restriction of the use of certain hazardous substances in electrical and electronic equipment, http://www.eur-lex.europa.eu/legal-content/en/TXT/?uri=celex:32011L0065

14. M.Kama, T.Shiratori. Contribution of Asian industries to hazardous substances management and e-waste recycling // Engineering Journal, 2016, N4, p-p.1-10

15. 14. RoHS Declaration of Conformity, http://www.kingston.com/en/company/environment

16. UNEP, the Minamata Mercury Convention, http://www.mercuryconvention.org

17. Directive 2006/66 / EC of the European Parlament and of the Council. September 2006. On batteries and accumulators and waste batteries and accumulators and repealing Directive 91/157 / EEC, http://www.eurlex.europa.eu

18. http://www.eur-lex.europa.eu/legal-content/EN/TXT/?uri=CELEX\%3A32006L006

19. The State Statistics Committee of the Republic of Azerbaijan, http://www.stat.gov.az/source/environment/az/bul/evr_04_2016.pdf

20. Why do I need air ionization? http://www.medicina.dobro-est.com/ionizatsiya-vozduha.html

21. The hazard class of toner chemicals, http://www.greenologia.ru/utilizaciyatexniki/ofisnaya/nelzya-vybrasyvat-kartridzhy.html

22. IEC 62471:2006, Photobiological safety of lamps and lamp systems,

23. http://www.en-standard.eu/iec-62471-2006-photobiological-safety-of-lamps-and-lampsystems/?gclid=COiOiL65u8wCFWQq0wodjf0DCw

24. Behar-Cohen F. et al. Light-emitting diodes (LED) for domestic lighting: Any risks for the eye? // Progress in retinal and eye research. 2011, vol. 30, pp. 239-257. 